\section{SUMMARY}

This study demonstrates that the newborn lamb, in order to adapt to extrauterine life, requires erythrocytes with a lower oxygen affinity than that which existed near the end of fetal life. But because the red cells at birth contain predominantely fetal hemoglobin, an adequate $P_{50}$ can only be attained by a marked increase in red cell DPG. The amount of DPG required depends upon the quantity of adult hemoglobin present within the red cell at birth. When enough DPG has been attained for an adequate postnatal $\mathrm{P}_{50}$ the quantity then decreases synchronously with the increase in adult hemoglobin in an orderly fashion so that adequate $P_{50}$ values are maintained. The need for a rise in DPG concentration postnatally can be aborted by providing the newborn lamb with adequate amounts of adult hemoglobin, such as by an exchange transfusion with adult blood.

\section{REFERENCES AND NOTES}

I. Battaglia, F. C., McGaughey, H., Makowski, E. L., and Meschia, G.: Postnatal changes in oxygen affinity of sheep red cells: a dual role of diphosphoglyceric acid. Amer. J. Physiol., 219: 217 (1970).
2. Bunn, H. F., and Briehl, R. W.: The interaction of 2,3-diphosphoglycerate with various human hemoglobins. J. Clin. Invest., 49: 1088 (1970).

3. Dozy, A. M., Kleihauer, E. F., and Huisman, T. H. J.: Studies on the heterogeneity of hemoglobin. XIII. Chromatography of various human and animal hemoglobin types on DEAE-Sephadex. J. Chromatogr., 32: 723 (1968).

4. Hilpert, P., Fleischmann, R. C., Kempe, D., and Bartels, H.: The Bohr effect related to blood and erythrocyte pH. Amer. J. Physiol., 205(2): 337 (1963).

5. Keitt, A. S.: Reduced nicotinamide adenine dinucleotide-linked analysis of 2,3-diphosphoglyceric acid: Spectrophotometric and fluorometric procedures. J. Lab. Clin. Med., 77: 470 (1971).

6. Versmold, H., Seigert, G., and Riegel, K. P.: Blood oxygen affinity in infancy: The interaction of fetal and adult hemoglobin, oxygen capacity and red cell hydrogen ion and 2,3-diphosphoglycerate concentration. Resp. Physiol., 18: 14 (1973).

7. St. Louis, Mo.

8. Instrumentation Laboratory, Inc. Lexington, Mass.

9. Lexington Instruments Corp., Waltham, Mass.

10. The authors are grateful for the technical assistance provided by Mr. Andrew Bator, B.Sc.

11. This research was supported by Grant MA-5120 from the Medical Research Council of Canada.

12. Requests for reprints should be addressed to: H. Bard, M.D., Department of Pediatrics, Hôpital Sainte-Justine, 3175 Chemin Sainte-Catherine Montreal, Quebec H3T 1C5 (Canada).

13. Accepted for publication April 19, 1976.
Gas chromatography

D-glyceric acid

D-glyceric dehydrogenase hydroxypyruvic acid mass spectrometry nonketotic hyperglycinemia

\title{
D-Glyceric Acidemia: Biochemical Studies of a New Syndrome
}

\author{
S. K $\varnothing$ LVRAA, ${ }^{(32)}$ K. RASMUSSEN, AND N. J. BRANDT \\ Biochemical Research Unit, Department of Clinical Chemistry, University of Aarhus, Denmark and Department of \\ Teratology, University of Copenhagen, Rigshospitalet, Copenhagen, Denmark
}

\section{Extract}

Studies of a mentally retarded boy, clinically suffering from nonketotic hyperglycinemia, are reported. Using combined gas chromatography-mass spectrometry, enzyme specificity studies, and spectropolariometry D-glyceric acid in extremely elevated concentrations was demonstrated in both serum and urine (serum: 1.0-1.3 mmol/liter, urine: 33-187 mmol/liter). Hydroxypyruvic acid was not detectable in urine from this boy using a gas chromatographic method with a limit of detection of $0.3 \mathrm{mmol} /$ liter. Enzyme assays of D-glyceric dehydrogenase on blood leukocytes demonstrated significantly lower activity in the patient compared with five normal children.

\section{Speculation}

The accumulation of glycine in this new metabolic defect may result from a secondary inhibition of the glycine cleavage system, an explanation that would correspond well with the current concept on the genesis of the glycine accumulation found in ketotic hyperglycinemia.

Recently we had the opportunity to investigate a 4-year-old boy, clinically suffering from nonketotic hyperglycinemia, who con- stantly excreted large amounts of another compound besides glycine. This compound was identified as glyceric acid $(3,4)$.

Accumulation of this compound has not previously been reported in hyperglycinemic conditions. The original hyperglycinemia syndrome $(7,18)$, exists in two clinically distinct entities, a ketotic and a nonketotic form. The ketotic form is characterized by excretion of other metabolites besides glycine, i.e., organic acids derived from the breakdown of branched chain amino acids, and it is now firmly documented that also the primary enzyme defect is located here (16). The hyperglycinemia in these disorders is assumed to be a secondary phenomenon. In contrast, all so far available evidence indicates that nonketotic hyperglycinemia is caused by a primary defect in the glycine cleavage system, and it has never been possible to demonstrate accumulation of other metabolites besides glycine (17).

Hyperglyceric aciduria has previously been described only in primary hyperoxaluria type 2 , a condition characterized by recurrent nephrolithiasis and excretion of oxalic acid and L-glyceric acid $(25,26)$. However, hyperglycinemia is not a feature in this disorder.

The purpose of this paper is to present biochemical studies on our patient. It is shown that the glyceric acid excreted in this new metabolic disorder is the D-stereoisomer, and that the accumulation of this compound presumably results from an enzyme defect of the D-glyceric dehydrogenase. 


\section{CASE REPORT}

$A . J$. is the second child of nonconsanguineous emigrants from Serbia, whose first child, a boy, was normal. He was born after a full term pregnancy and spontaneous delivery. Birth weight was $3,350 \mathrm{~g}$. From the first days of life severe hypotonia was observed, and spontaneous movements were almost totally absent. At 8 weeks of age generalized seizures appeared, and the child was admitted to the neuropediatric ward. During this admission he has presented several unusual neurologic symptoms such as myoclonic jerks, cerebellar fits, and an almost classic chorea minor pattern (4). Since this admission he has failed to develop mentally, and is now at an age of 4 years still totally helpless and has no contact with his surroundings. He still has frequent episodes of generalized seizures in spite of antiepileptic treatment. Physically he is normally developed with a weight corresponding to his age. Normal laboratory results included routine urine analyses, complete blood count, and concentrations of serumelectrolytes, protein, glucose, creatinine, uric acid, and bilirubin. Arterial acid-base values were normal both during his better periods and during relapses, and ketosis was never present. Urinary excretion of oxalic acid was normal. Abnormal laboratory findings were moderately elevated concentrations of alkaline phosphatase, 2-hydroxybutyrate dehydrogenase, and aspartate aminotransferase.

Amino acid screening, prompted by the clinical picture, showed severely elevated concentrations of glycine in serum, spinal fluid, and urine (in serum $0.3-1.5 \mathrm{mmol} / \mathrm{liter}$; in spinal fluid $0.12 \mathrm{mmol} /$ liter; in urine $22-61 \mathrm{mmol} / 24 \mathrm{hr}$ ). All other amino acids were within the normal range (4).

From the clinical picture and the hyperglycinemia we concluded that the patient had a typical syndrome of nonketotic hyperglycinemia. However, when a routine gas chromatographic screening for organic acids was performed using the method of Ando et al. $(1,2)$, large amounts of an unknown compound were found repeatedly. Significant amounts of propionic acid, methylmalonic acid, or isovaleric acid were never found.

\section{MATERIALS AND METHODS}

Lactic dehydrogenase (pig muscle, EC.1.1.1.27), D-glyceric dehydrogenase (spinach leaves, EC.1.1.1.26) and $\beta$-adenine dinucleotide (NAD) were purchased from Boehringer Mannheim, West Germany. Alkaline phosphatase (calf intestinal mucosa, EC.3.1.3.1) were obtained from Sigma Chemical Co., St. Louis. D-Glyceric acid was synthesized from 3-D-phosphoglyceric acid (27) by treatment with alkaline phosphatase and purified by the method used for isolation of glyceric acid from the patient's urine.

The organic acids were extracted from the urine with equal amounts of diethylether and ethylacetate. A urine specimen equivalent to $2 \mathrm{mg}$ creatinine was acidified with $1 \mathrm{~N} \mathrm{HCl}$ and equal amounts of saturated sodium chloride were added. Extraction was performed using 10 volumes of diethylether and 10 volumes of ethylacetate. The combined organic phase was dried with anhydrous sodium sulfate and evaporated under a stream of dry nitrogen. The organic acids in the residue were derivatized as either trimethylsilyl esters-trimethylsilyl ethers (TMS derivatization) by adding $0.2 \mathrm{ml}$ Tri-Sil (28) and $0.2 \mathrm{ml} \mathrm{N}, \mathrm{O}$-bis-(trimethylsilyl)trifluoroacetamide (BSTFA) (28) or as methyl esters trimethylsilyl ethers (ME-TMS derivatization) by initial methylation after the method of Schlenk et al. (21) followed by addition of $0.2 \mathrm{ml} \mathrm{Tri-Sil}$ and $0.2 \mathrm{ml}$ BSTFA. Aliquots of $3 \mu 1$ were injected into the gas chromatographic column. Gas chromatography was carried out using a Hewlett-Packard 7620 A instrument equipped with a 6 -foot by $1 / 8$-inch (inner diameter) glass column packed with $3 \%$ OV I on Chromosorb W, HP 80/100 mesh (28). Helium was used as carrier gas (flow: $60 \mathrm{ml} / \mathrm{min}$ ), and in the routine investigation the oven was programmed at $4 \% \mathrm{~min}$ from $60^{\circ}$ to $260^{\circ}$.

Gas chromatography-mass spectrometry was carried out using a
Pye-Unicam 104 gas chromatograph coupled via an all glass line and a silicone membrane separator to an AEI MS 30 mass. spectrometer. The gas chromatograph was fitted with a 6-foot by $1 / 8$-inch glass column packed with $3 \%$ OV I. Helium was used as carrier gas.

\section{GLYCERIC ACID IN URINE}

The unknown gas chromatographic peak was identified as glyceric acid by its retention time expressed relative to alkanes in methylene unit (MU) values after the method of Dalgliesh et al. (10), and by mass spectrometry. The glyceric acid concentration in urine was determined using aqueous solutions of calcium-D,L-glycerate (27) as standards. Both urine specimens and standards were extracted with diethylether and ethylacetate as described above, and the glyceric acid was quantified by gas chromatography using silylated derivatives. The extraction yield of glyceric acid was estimated by comparing the peak areas of glyceric acid obtained from urine after extraction and TMS derivatization with those obtained after direct TMS derivatization of the lyophilized urine.

Glyceric acid was isolated from $A J$ 's urine in order to determine its stereoisomer form. Twenty grams of charcoal were added to $\mathrm{ml}$ urine. After heating to $50^{\circ}$ for $30 \mathrm{~min}$ centrifugation was performed and the supernatant was applied to a Dowex 1 column. Eluation was done with rising concentrations of acetic acid $(0.5-2.0 \mathrm{~N})$. The eluate was collected in fractions and tested by gas chromatography for glyceric acid. The fractions containing glyceric acid were combined, and acetic acid and water were evaporated in varuo at $50^{\circ}$. The residue was redissolved in distilled water and tested by gas chromatography for impurities.

The glyceric acid isolated from the patient's urine was incubated with NAD and either lactic dehydrogenase or D-glyceric dehydrogenase. The reaction mixture was comprised of: glycine $1 \mathrm{mmol}$, pH 9; hydrazine sulfate $0.8 \mathrm{mmol}, \mathrm{pH} 9$; NAD $0.8 \mu \mathrm{mol}$; D-glyceric dehydrogenase $200 \mu 1$ or lactic dehydrogenase $200 \mu$ l. The reaction was started by adding $50 \mu \mathrm{l}$ glyceric acid solution $(20$ $\mathrm{mM}$ ). The total volume was $2,280 \mu 1$ and the reaction took place at $37^{\circ}$. The oxidation of glyceric acid was measured on a Zeiss PMQ 11 spectrophotometer at $340 \mathrm{~nm}$. Aqueous solutions of calcium-D, L-glycerate $(25 \mathrm{mM}$ and $6.25 \mathrm{mM})$ were used as references. The optical rotation of an aqueous sample of glyceric acid isolated from the patient's urine was measured on a Spectropol 1 FICA apparatus. A sample of authentic D-glyceric acid of a similar concentration $(20 \mathrm{mM})$ was used as reference.

\section{GLYCERIC ACID IN SERUM}

The serum concentration of glyceric acid was determined by the same method as urinary glyceric acid, except that serum specimens were treated with ethanol to precipitate the proteins before extraction.

\section{HYDROXYPYRUVIC ACID}

A gas chromatographic method for determination of urinary hydroxypyruvic acid was designed using the method for ketoaciddetermination described by Lancaster (15). A urine specimen was made strongly alkaline, and extracted with diethylether. The organic phase was discharged. Hydroxylamine (29) was added, and after heating at $60^{\circ}$ for 30 min the sample was acidified and again extracted with diethylether. The extract was dried, evaporated and TMS derivatized. Gas chromatography was performed on a $3 \%$ OV I column.

\section{D-GLYCERIC DEHYDROGENASE IN LEUKOCYTES}

Blood corresponding to $5 \times 10^{7}$ leukocytes was drawn from the patient on two occasions with an interval of 10 days. In the first experiment two children, age 2 and 6 years, and in the second experiment three children, age 3-6 years, were used as control subjects. All five control children were without signs of metabolic disorder. The leukocytes were isolated by the dextran method (8), 
and remaining erythrocytes were removed by hypo-osmolar disrupture. The final pellets were dissolved in $2 \mathrm{ml} 0.154 \mathrm{M}$ potassium chloride containing $0.01 \mathrm{M} \beta$-mercaptoethanol, and homogenized by $4 \mathrm{~min}$ of sonication. After centrifugation at $2,700 \times g$ for 30 min, $1 \mathrm{M}$ magnesium chloride, $50 \mu \mathrm{l}$, was added, and the solutions were dialyzed for $36 \mathrm{hr}$ against $0.06 \mathrm{M}$ sodium acetate containing $0.01 \mathrm{M} \beta$-mercaptoethanol at $4^{\circ}$. After another centrifugation the supernatants were used in the enzyme assays. These were performed on an Aminco SPF 125 spectrofluorometer. The reaction mixture was comprised of: Tris $0.2 \mathrm{mmol}, \mathrm{pH} \mathrm{9}$; hydrazine sulfate $0.4 \mathrm{mmol}, \mathrm{pH} 9$; NAD $9 \mu \mathrm{mol}$; D-glyceric acid $3.5 \mu \mathrm{mol}$; and enzyme suspension corresponding to $2 \times 10^{6}$ leukocytes. The total volume was $2,800 \mu \mathrm{l}$. The reaction took place at $30^{\circ}$ in the cuvette after addition of the D-glyceric acid. The formation of reduced $\beta$-adenine dinucleotide (NADH) was followed using an excitation wave length at $340 \mathrm{~nm}$ and an emission wave length at $460 \mathrm{~nm}$.

\section{RESULTS}

\section{GLYCERIC ACID IN URINE}

Both TMS- and ME-TMS derivatives were used to identify the unknown compound found in the routine gas chromatographic screening. In both cases a large peak was found. The gas chromatogram obtained using ME-TMS derivatives is shown in Figure 1. The mass spectrums obtained, when using the two different types of derivatives, showed molecular ions of 322 (TMS) and 264 (ME-TMS), respectively. This difference indicates that the unknown compound had only one carboxyl group. The ion at $\mathrm{m} / \mathrm{e} 147$ in the mass spectrum of the ME-TMS derivative (Fig. 2) indicates the presence of at least two TMS groups (19). Based on these observations glyceric acid was suspected. To confirm this assumption the MU values of the unknown compound and of authentic glyceric acid were measured, and found to be identical on two different gas chromatographic columns, as shown in Table 1.

The final identity was established by mass spectrometry, since the mass spectrums obtained from the unknown compound and from authentic glyceric acid were identical, using both ME-TMS derivatives (Fig. 2) and TMS derivatives.

The relationship between the detector response and the sample size of the TMS-derivatized authentic glyceric acid was linear through 0 over the range tested $(1-10 \mathrm{mmol} / \mathrm{liter})$. The correlation coefficient for the standard curve was 0.99 . The recovery of glyceric acid through the extraction procedure was about $13 \%$.
Over a period of 2 years the urinary concentration of glyceric acid measured by this method ranged from 33 to $187 \mathrm{mmol} /$ liter.

When the patient's charcoal-treated urine was chromatographed on a Dowex 1 column, glyceric acid was eluated as a well defined peak at $1.0-1.5 \mathrm{~N}$ acetic acid. When tested by gas chromatography for impurities using TMS derivatives as well as ME-TMS derivatives, the glyceric acid peak was found to contain only minor impurities, amounting to less than $1 \%$, estimated by peak areas.

The glyceric acid isolated from the patient was oxidized when incubated with D-glyceric dehydrogenase, but not when incubated with lactic dehydrogenase. D,L-Glyceric acid was oxidized equally in both systems (Fig. 3). When authentic D-glyceric acid was used as a substrate in the two assays, it behaved like the glyceric acid from the patient.

The optical rotation of the glyceric acid was measured between $240 \mathrm{~nm}$ and $350 \mathrm{~nm}$ (Fig. 4). The patient was found to excrete D-glyceric acid, since a descending optical rotatory dispersion curve was obtained with descending wave length in the interval tested (9). When measuring authentic D-glyceric acid under the same conditions, an identical curve was obtained.

\section{GLYCERIC ACID IN SERUM}

The concentration of glyceric acid in serum was $1.0-1.3$ $\mathrm{mmol} /$ liter.

\section{HYDROXYPYRUVIC ACID}

The method designed to quantify urinary hydroxypyruvic acid proved to be usable. The standard curves obtained were straight (correlation coefficient 0.98 ), and passed through 0 . The mass spectrum of the gas chromatographic peak was consistent with the expected hydroxylamine-TMS-derivatized hydroxypyruvic acid $(M=335)$. The limit of detection was less than $0.3 \mathrm{mmol} / \mathrm{liter}$. It was never possible to demonstrate the presence of hydroxypyruvic acid in any urine specimen from the patient.

\section{D-GLYCERIC DEHYDROGENASE IN LEUKOCYTES}

Figure 5 shows the formation of NADH in the reaction mixture as a function of time elapsed after additon of D-glyceric acid. The design of the fluorometer made it necessary to delay the first measurement $30 \mathrm{sec}$. Each point represents the difference between the formation of $\mathrm{NADH}$ in the total sample (i.e., the assay containing the total reaction mixture + D-glyceric acid) and the corresponding sample blind (i.e., reaction mixture + distilled

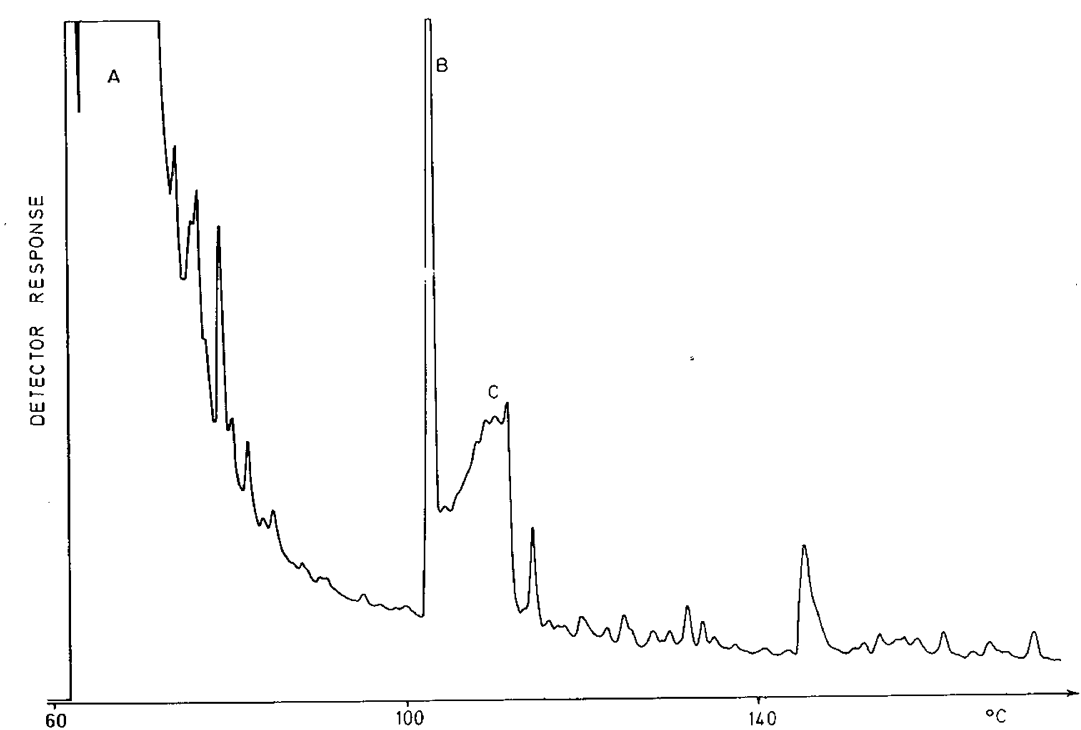

Fig. I. Gas chromatogram of methyl esters-trimethylsilyl ethers derivatives of urine organic acids from $A J$. Column: $3 \%$ OV I. $A$ : solvent front; $B$ : glyceric acid; $C$ : urea 


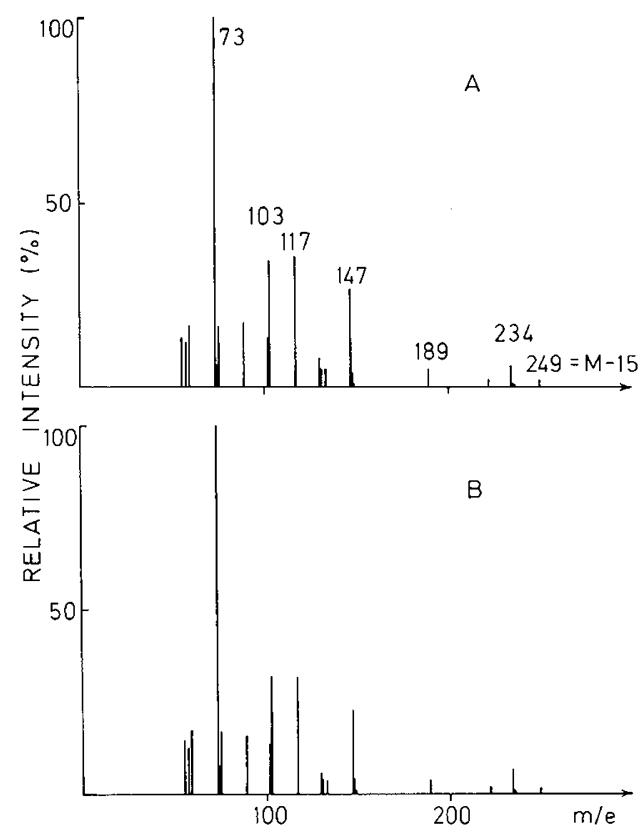

Fig. 2. Mass spectrum of the unknown compound using methyl esterstrimethylsilyl ethers derivatives $(A)$ compared with that obtained from authentic glyceric acid $r$

Tau. 1. Methylene unit values ${ }^{1}$

\begin{tabular}{clcc}
\hline Column & Derivative & $\begin{array}{c}\text { Authentic } \\
\text { glyceric } \\
\text { acid }\end{array}$ & $\begin{array}{c}\text { Abnormal } \\
\text { peak }\end{array}$ \\
\hline \multirow{2}{*}{$3 \%$ OV-1 } & ME + TMS & 12.41 & 12.41 \\
& TMS & 13.52 & 13.48 \\
$3 \%$ OV-17 & ME + TMS & 13.21 & 13.22 \\
& TMS & 13.83 & 13.83 \\
\hline
\end{tabular}

${ }^{1}$ ME: methyl esters; TMS: trimethylsilyl ethers and esters.

water instead of D-glyceric acid). The approximated line for each experiment was calculated using the principle of least squares (22), and the regression coefficients of these lines were used as measurements of enzyme activity.

Significant D-glyceric dehydrogenase activity was found in leukocytes from the patient, since the activity in the total sample was significantly higher than the activity in the corresponding sample blind $(P<0.025$ ( $t$-test $))$. The $95 \%$ confidence limits of the activities found in the two experiments with leukocytes from the patient were $0.4-1.2 \mathrm{nmol} \mathrm{NADH} / \mathrm{min}$ to $0.4-2.1 \mathrm{nmol}$ $\mathrm{NADH} / \mathrm{min}$. The mean enzyme activity of the five normal children was $3.3 \mathrm{nmol} \mathrm{NADH} / \mathrm{min}$ (range: $2.6-4.0 \mathrm{nmol} \mathrm{NADH} /$ $\min$ ).

In a separate experiment equal amounts of leukocyte homogenate from the patient and from one of the normal children were pooled, and the D-glyceric dehydrogenease activity was measured. The activity found was slightly higher, but not significantly different from the expected value, which in this experiment is the mean of the values obtained when enzyme activity was measured in leukocytes from the two children separately.

\section{DISCUSSION}

The original "idiopathic hyperglycinemia" described by Childs et al. (7) and Nyhan et al. (18) was later divided into two clinically distinct entities, namely a ketotic variant with recurrent attacks of ketoacidosis and a nonketotic variant without ketoacidosis, but with early signs of progressive cerebral damage $(16,17)$. It is now clear that the ketotic form represents several well defined inborn errors of metabolism, such as propionic acidemia, methylmalonic acidemia, and isovaleric acidemia, and it is assumed that the hyperglycinemia found in these diseases is a secondary phenomenon. In contrast, all so far available evidence indicates that the syndrome nonketotic hyperglycinemia is caused by a primary block in the glycine cleavage system.

Therefore, the most striking difference between our patient and all the previously described cases of nonketotic hyperglycinemia is the accumulation of another compound besides glycine. This compound was identified as glyceric acid by its gas chromatographic behavior in several systems and by mass spectrometry.

Glyceric acid is an unusual metabolite to find in human urine. In the routine gas chromatographic screening of urine from 400 children suspected as having metabolic disorder and from 50 healthy children, we have never found this compound in any urine except from the patient presented.

Chalmers et al. (5) found trace amounts of glyceric acid in urine from a patient with propionic acidemia when using DEAESephadex ion exchange chromatography to extract the organic acids. This method probably gives a much higher extraction yield of glyceric acid than the method used in the present investigation.

L-Glyceric aciduria has been described by Williams and Smith
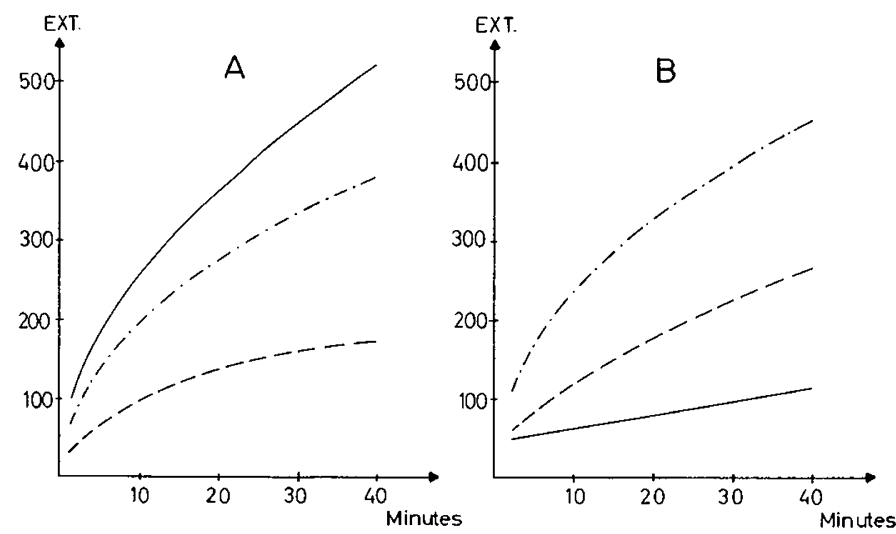

Fig. 3. Determination of stereoisomer form of the glyceric acid isolated from the patient's urine using enzyme specificity. Formation of reduced adenine dinucleotide in a system containing D-glyceric dehydrogenase $(A)$ and in a system containing lactic dehydrogenase $(B)$. The reactions were started by adding $50 \mu \mathrm{l}$ of either $20 \mathrm{mM}$ glyceric acid from the patient $(-)$ or $25 \mathrm{mM}$ calcium-D, L-glycerate (-.-.-) or $6.25 \mathrm{mM}$ calcium$\mathrm{D}, \mathrm{L}$-glycerate $(---)$.

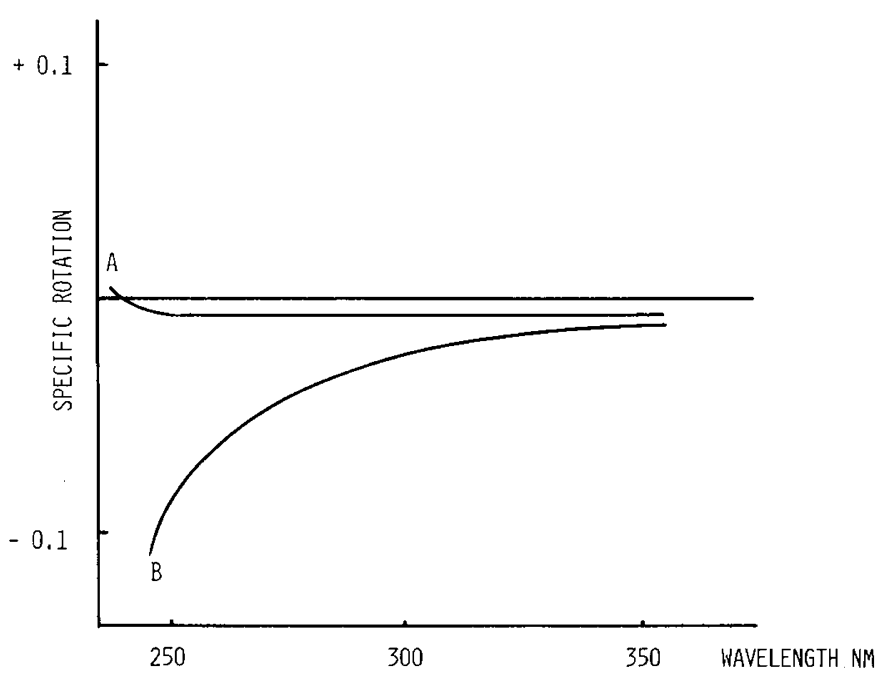

Fig. 4. Optical rotatory dispertion curves. $A$ : distilled water; $B$ : an aqueous solution of glyceric acid from the patient. 
$(25,26)$ in four patients with primary hyperoxaluria type 2. However, these patients were characterized clinically only by recurrent calcium oxalate nephrolithiasis, and showed no signs of cerebral damage. No hyperglycinemia was found, but in all four patients large amounts of oxalic acid and L-glyceric acid was excreted. No glyceric acidemia was reported. Thus the clinical and biochemical picture in our patient is fundamentally different from that in primary hyperoxaluria type 2 .

Recently, Wadman (23) has found elevated concentration of glyceric acid in both serum and urine from a 4-week-old boy with recurrent attacks of metabolic acidosis. The evaluation of this syndrome is difficult, since the optical configuration of the glyceric acid still has to be determined, but neither hyperglycinemia nor hyperoxaluria was present.

The optical form of the glyceric acid excreted by our patient was determined using two different principles, as described by Williams (25). The enzymatic method is based on the fact that L-glyceric acid together with lactic acid is the substrate for lactic dehydrogenase, and that D-glyceric acid together with glycolic acid is the substrate of D-glyceric dehydrogenase (1i). The reduction of NAD in the two assays would therefore depend solely on whether the glyceric acid from the patient has the D or L stereoisomer form. As shown in Figure 3 the glyceric acid excreted is the D form. This was further confirmed by spectropolariometry (Fig. 4).

It is difficult to imagine a common enzyme block, that can explain the accumulation of both glycine and glyceric acid. It is therefore proposed that the glycine accumulation is secondary to the organic acidemia. This would correspond well with the current concept on the hyperglycinemia seen in the organic acidurias presenting with ketotic hyperglycinemia. The possibility that the D-glyceric acid accumulation could be secondary to the glycine accumulation, can be excluded, since no D-glyceric aciduria has been found in the previously described cases of hyperglycinemia.

Therefore, our further investigations were centered on the cause of the D-glyceric acid accumulation. Several authors have defined $\mathrm{D}$-glyceric acid as an intermediate in the interconversion between serine and glucose. Two pathways are operating here involving either phosphorylated or nonphosphorylated intermediates (Fig. 6). The nonphosphorylated pathway includes 2-phosphoglyceric acid, D-glyceric acid, and hydroxypyruvic acid. The interconversion between 2-phosphoglyceric acid and D-glyceric acid is catalyzed by two different enzymes, 2-phosphoglyceric phosphatase and D-glyceric kinase (12), whereas the D-glyceric acid-hydroxypyruvic acid interconversion is catalyzed by D-glyceric dehydrogenase.

Several authors have studied the nonphosphorylated pathway,

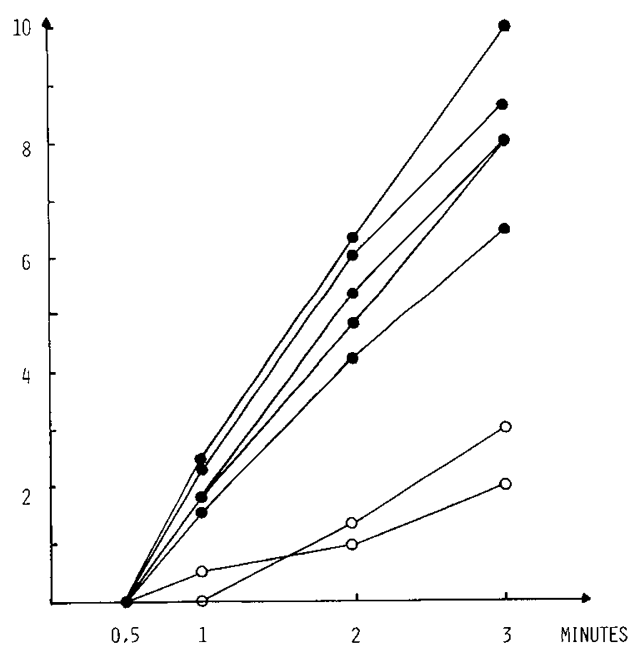

Fig. 5. D-Glyceric dehydrogenase in leukocytes. Formation of reduced adenine dinucleotide in nanomoles per $10^{7}$ leukocytes in the interval of $0.5-3 \mathrm{~min}$ after addition of D-glyceric acid for normal children $(-)$ ) and for the patient $(\mathrm{O}-\mathrm{O})$.

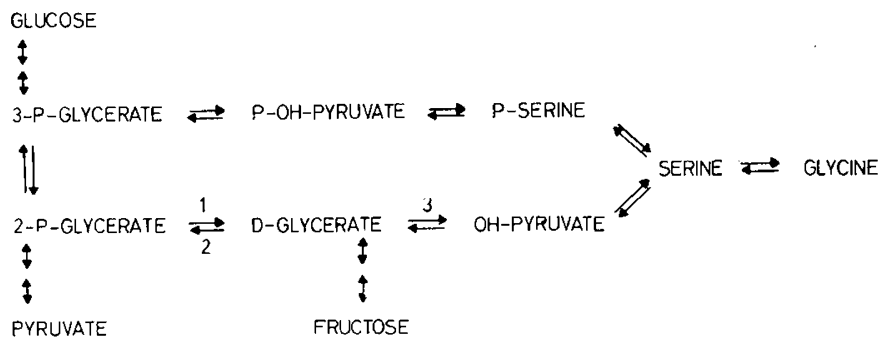

Fig. 6. Pathways between serine and carbohydrate intermediates. The upper pathway is the "phosphorylated" and the lower the "nonphosphorylated" pathway. 1: 2-P-glycerate phosphatase; 2: D-glycerate kinase; 3: D-glycerate dehydrogenase.

and the evidence presented indicates that it can operate both as a glyconeogentic pathway and as a pathway for biosynthesis of serine $(6,13,14,24)$.

Based on the lack of leukocyte D-glyceric dehydrogenase in patients with primary hyperoxaluria type 2 , Williams et al. explained the accumulation of L-glyceric acid by assuming that the pathway was operating from serine, through hydroxypyruvic acid to glyceric acid. The resulting accumulated hydroxypyruvic acid would in turn be converted to L-glyceric acid, catalyzed by lactic dehydrogenase. However, Williams was not able to demonstrate an accumulation of hydroxypyruvic acid in his patients.

D-Glyceric acid may also be formed from fructose via D-glyceraldehyde. Experiments with intraportal infusion of radioactively labeled fructose has lead to the conclusion that this pathway might be of major importance in the metabolism of fructose (20), and consequently may be the major source of D-glyceric acid. It is therefore reasonable to expect that a deficiency in either D-glyceric kinase or D-glyceric dehydrogenase could be the cause of the D-glyceric acid accumulation. The finding that the patient did not excrete significant amounts of hydroxypyruvic acid led us to investigate the D-glyceric dehydrogenase.

In these experiments D-glyceric dehydrogenase activity was found in leukocytes from both the control children and from the patient, but the amount found in the patient's leukocytes was significantly smaller than the amount found in leukocytes from the control children.

No inhibition of the D-glyceric dehydrogenase activity in leukocytes from a normal child was demonstrated when pooled with leukocyte homogenate from the patient. This documents that the diminished activity found in the patient's leukocytes is not caused by enzyme inhibition. It is therefore proposed that a deficiency of D-glyceric dehydrogenase causes the accumulation of D-glyceric acid. Why the same enzyme defect in primary hyperoxaluria type 2 results in an entirely different picture is unexplained at present time and must await further investigations. The hyperglycinemia in our patient is also unexplained, but studies on the glycine cleavage system are in progress in this laboratory and will be published later.

\section{SUMMARY}

Besides glycine, large amounts of another compound were found repeatedly in urine and serum from a 4-year-old boy who presented with nonketotic hyperglycinemia clinically. This compound was identified as D-glyceric acid by combined gas chromatographymass spectrometry, substrate specificity studies and optical rotatory dispersion curves. A deficiency of leukocyte D-glyceric dehydrogenase was demonstrated.

\section{REFERENCES AND NOTES}

1. Ando, T., Nyhan, W. L., Bachmann, C., Rasmussen, K., Scott, R., and Smith, E $\mathrm{K}:$ Isovaleric acidemia: Identification of isovalerate, isovalerylglycine, and 3-hydroxyisovalerate in urine of a patient previously reported as having butyric and hexanoic acidemia. J. Pediat., 82: 243 (1973). 
2. Ando, T., Rasmussen, K., Nyhan, W. L., Donnell, G. N., and Barnes, N. D. Propionic acidemia in patients with ketotic hyperglycinemia. J. Pediat., 78: 827 (1971).

3. Brandt, N. J., Brandt, S., Rasmussen, K., and Sch $\phi$ nheyder, F.: Hyperglycericacidaemia with hyperglycinaemia: A new inborn error of metabolism. Brit. Med. J., IV: 344 (1974)

4. Brandt, N. J., Rasmussen, K., Brandt, S., K $\phi$ lvraa, S., and Sch $\phi$ nheyder, F.: D-Glyceric acidaemia and non-ketotic hyperglycinaemia. Acta Paediat. Scand., 65: 17 (1976).

5. Chalmers, R. A., Lawson, A. M., and Watts, R. W. E.: Studies on the urinary acidic metabolites excreted by patients with $\beta$-methylcrotonylglycinuria, propionic acidemia and methylmalonic acidemia, using gas-liquid chromatography and mass spectrometry. Clin. Chim. Acta, 52: 43 (1974).

6. Cheung, G. P., Cotropia, J. P., and Sallach, H. J.: The effects of dietary protein on the hepatic enzymes of serine metabolism in the rabbit. Arch. Biochem. Biophys., 129 (1969).

7. Childs, B., Nyhan, W. L., Borden, M., Bard, L., and Cooke, R. E.: Idiopathic hyperglycinemia and hyperglycinuria, a new disorder of amino acid metabolism. Pediatrics, 27: 522 (1961)

8. Cohn, J., Wang, P., Hauge, M., Henningsen, K., Jensen, B., and Svejgaard, A.: Amylo-1,6-glucocidase deficiency (glycogenosis type III) in the Faroe Islands. Hum. Hered., 25: 115 (1975).

9. Craig, J. C., and Roy, S. K.: Optical rotatory dispersion and absolute configuration. IV. Tetrahedron, 21: 1847 (1965).

10. Dalgliesh, C. E., Horning, E. C., Horning, M. G., Knox, K. L., and Yarger, K.: A gas-liquid-chromatographic procedure for separating a wide range of metabolites in urine or tissue extracts. Biochem. J., 101: 792 (1966).

11. Dawkins, P. D., and Dickens, F.: The oxidation of D- and L-glycerate by rat liver. Biochem. J., 94: 353 (1965)

12. Fallon, H. J., and Burne, W. L.: 2-Phosphoglyceric acid phosphatase: Identification and properties of the beef-liver enzyme. Biochim. Biophys. Acta, 105: 43 (1965)

13. Fallon, H. J., Hackney, E. J., and Byrne, W. L.: Serine biosynthesis in rat liver. J. Biol. Chem., 241: 4157 (1966).

14. Fallon, H. J., and Byrne, W. L.: Depression of enzyme activity by cortisone: An effect on serine metabolism. Endocrinology, 80: 847 (1967).

15. Lancaster, G. A.: Measurement of keto- and hydroxy-acids. Application of gas chromatography-mass spectrometry to the investigation of human disease. Proceedings of a Workshop, Montreal, 1973

16. Nyhan, W. L.: Propionic acidemia and the ketotic hyperglycinemia syndrome. In: W. L. Nyhan: Heriditable Disorders of Amino Acid Metabolism, p. 37 (John Wiley and Sons, New York, 1974).

17. Nyhan, W. L.: Non-ketotic hyperglycinemia. In: W. L. Nyhan: Heriditable Disorders of Amino Acid Metabolism, p. 309 (John Wiley and Sons, New York, 1974).

18. Nynan, W. L., Borden, M., and Childs, B.: Idiopathic hyperglycinemia, a new disorder of amino acid metabolism. II. The concentrations of other amino acids in the plasma and their modification by the administration of leucine. Pediatrics, 27: 539 (1961).

19. Pierce, A. E.: Silylation of Organic Compounds, Chapt. 3 (Pierce Chemical Co., Rockford, Ill., 1968)

20. Rauschenbach, P., and Lamprecht, W.: Einbau von $C^{14}$-markierter glucose und fructose in Leberglycogen. Z. Physiol. Chem., 339: 277 (1964).

21. Schlenk, H., and Gellerman, J. L.: Esterification of fatty acids with diazomethane on a small scale. Anal. Chem., 32: 1412 (1960).

22. Sokal, R. R., and Rohlf, F. J.: Biometry, Chapt. 14 (W. H. Freeman and Co. 1969).

23. Wadman, S.K. Personal communication.

24. Walsh, D. A., and Sallach, H. J.: Comparative studies on the pathway for serine biosynthesis in animal tissue. J. Biol. Chem., 241: 4068 (1966).

25. Williams, H. E., and Smith, L. H.: The identification and determination of glyceric acid in human urine. J. Lab. Clin. Med., 71: 495 (1968)

26. Williams, H. E., and Smith, L. H.: L-glyceric aciduria, a new genetic variant of primary hyperoxaluria. New Engl. J. Med., 278: 233 (1968).

27. Sigma Chemical Co., St. Louis.

28. Pierce Chemical Co., Rockford, Ill

29. E. Merck, Darmstadt, Germany.

30. The authors wish to thank the Department of Medical Biochemistry, University of Arhus, for performing the spectropolariometric investigations.

31. This work has been supported by a grant from the Danish Medical Research Council.

32. Requests for reprints should be addressed to: S. Kфlvraa, M.D., Centrallaboratoriet, Århus kommunehospital, 8000 Århus C. (Denmark).

33. Accepted for publication May 4, 1976.

\section{Attempts to Induce Hepatic Uridine Diphosphate Glucuronyl Transferase in Genetically Deficient Gunn Rats by Grafting of Normal Liver Tissue*}

CORNELIS A. J. VAN HOUWELINGEN ${ }^{(10)}$ AND IRWIN M. ARIAS

Liver Research Center, Albert Einstein College of Medicine, New York, New York, USA

\section{Extract}

Liver from normal Wistar rats was grafted into the liver of homozygous Gunn rats which are deficient in UDP glucuronyl transferase (UDPGT) (bilirubin) activity. After 3 months, UDPGT activity (bilirubin) remained absent in microsomal suspensions of liver from recipient rats and no bilirubin glucuronide was detected in their bile.

\section{Speculation}

We were unable to confirm previous reports suggesting that transplantation of segments of normal rat liver into Gunn rat liver resulted in amelioration of jaundice because of UDPGT activity in the recipient liver.
Homozygous Gunn rats lack UDPGT activity with bilirubin as a substrate resulting in chronic nonhemolytic unconjugated hyperbilirubinemia (1). UDPGT activity is not enhanced in Gunn rats after treatment with phenobarbital (3).

Mukherjee and Krasner (7) transplanted small pieces of normal Wistar rat liver into the liver of Gunn rats and observed reduction in serum bilirubin concentations and virtually normal hepatic UDPGT activity (bilirubin) 3 months after the grafting procedure. Because these results have important implications for treatment of several human deficiency diseases, we repeated the experiment using similar animals and procedure. In addition, bile duct cannulation was performed in order to study the effect of liver grafting on the chemical nature of bile pigments. 